\title{
DESCRIÇÃO E AVALIAÇÃO DO MODELO DE ANÁLISE DE MERCADO EM EMPRESAS DE SEGMENTOS DISTINTOS
}

\author{
Rackel Raniere Durães Guerra (rackelranyery@hotmail.com) - Pontifícia Universidade Católica de \\ Minas Gerais - PUC Minas \\ Jenifer Silva de Oliveira (jenifersilva880@gmail.com) - Pontifícia Universidade Católica de Minas \\ Gerais - PUC Minas \\ Letícia Alexandre Furletti (leticiafurletti@gmail.com) - Pontifícia Universidade Católica de Minas \\ Gerais - PUC Minas \\ Priscilla Castro Leandro da Costa (pri.castro45@gmail.com) - Pontifícia Universidade Católica de \\ Minas Gerais - PUC Minas \\ Matheus Luiz Pontelo de Souza (mslzposa@gmail.com) - Pontifícia Universidade Católica de Minas \\ Gerais - PUC Minas
}

\section{RESUMO:}

Empresas habituadas a realizar análise de mercado, tem maior potencial em obter vantagens competitivas. Nesse sentido, há alguns modelos e conceitos úteis para orientar análises de mercado, como a análise de ambiente proposta pelo Business Model Generation e, em um nível mais estratégico, as cinco forças de Porter. Este trabalho descreve como é executada a análise de ambiente nas empresas e explicita em qual nível ela está relacionada com o arcabouço teórico citado. Para tanto, foi realizado um estudo de casos múltiplos com quatro empresas de setores e tamanhos distintos sobre a prática de análise de mercado. Os dados foram obtidos com a aplicação de um questionário semi-estruturado. Como contribuições principais estão à descrição de como é realizado o estudo de mercado nas organizações e uma análise crítica sobre a influência bibliográfica para tal tarefa. A proposição de melhoria aos modelos estudados complementa o trabalho. 


\section{INTRODUÇÃO}

O estudo das técnicas de mercado é importante para ajudar as empresas de diferentes áreas a tomar decisões estratégicas com mais segurança. De acordo com Osterwalder e Pigneur (2010) a análise constante do ambiente é mais importante que nunca, devido à crescente complexidade do panorama econômico e às severas perturbações do mercado. Os autores afirmam que compreender as mudanças no ambiente ajuda a empresa a se adaptar e lidar melhor com as variáveis externas.

Podemos encontrar inúmeras teorias referentes ao estudo de mercado, mas será que a prática das empresas ao realizar tais estudos é influenciada por essas teorias? Em qual nível? Com o intuito de esclarecer esse questionamento, foi realizado um estudo de casos múltiplos com quatro empresas de segmentos distintos que realizam constantemente análises/estudos de mercado.

As perspectivas teóricas escolhidas para elaborar o estudo tiveram por base a proposta de estudo de mercado do livro Business Model Generation (OSTERWALDER; PIGNEUR, 2010) e as indicações de pontos de análise oriundas do artigo The Five Competitive Forces That Shape Strategy (PORTER, 1979).

Por meio deste estudo foi possível entender e descrever como as empresas realizam o processo de análise de mercado e observar três critérios ao longo dos casos: i) o grau de importância de elementos contidos na análise de mercado para cada empresa; ii) o nível de formalidade da análise de mercado e iii) a influência da teoria na prática das empresas.

\section{REVISÃO TEÓRICA}

Osterwalder e Pigneur (2010) em um contexto de análise de mercado afirmam que desenvolver uma boa compreensão do ambiente da sua organização ajuda a conceber modelos mais sólidos e competitivos. Para Porter (1979), uma empresa ciente das cinco forças entende melhor a estrutura da empresa e pode buscar uma posição mais rentável e menos vulnerável a ataques. Os tópicos seguintes aprofundarão em algumas das proposições dos dois autores. Estes estudos foram escolhidos como pilares teóricos deste trabalho, conforme está abaixo detalhado. 


\subsection{Utilização do Business Model Generation para o Estudo de Mercado}

O Business Model Generation (BMG) foi proposto por Osterwalder e Pigneur (2010) como auxílio visual e prático à estruturação de modelos de negócio. Eles afirmam que com um modelo de negócios inovador, você pode até mesmo se tornar um transformador do ambiente, e definir novos padrões para seu segmento de atuação.

Os autores definem o ambiente como um contexto no qual você concebe ou adapta seu modelo de negócios, levando em consideração uma variedade de direcionadores (novas necessidades dos clientes, novas tecnologias, etc.) e restrições (tendências regulatórias, concorrentes dominantes, etc.).

Analisar este ambiente e compreendê-lo é importante para tomar decisões sobre o modelo de negócio e traçar direções mais assertivas (OSTERWALDER; PIGNEUR, 2010). Para auxiliar em tal análise, foi por eles proposto um mapeamento de quatro dimensões principais, conforme a Figura 1:

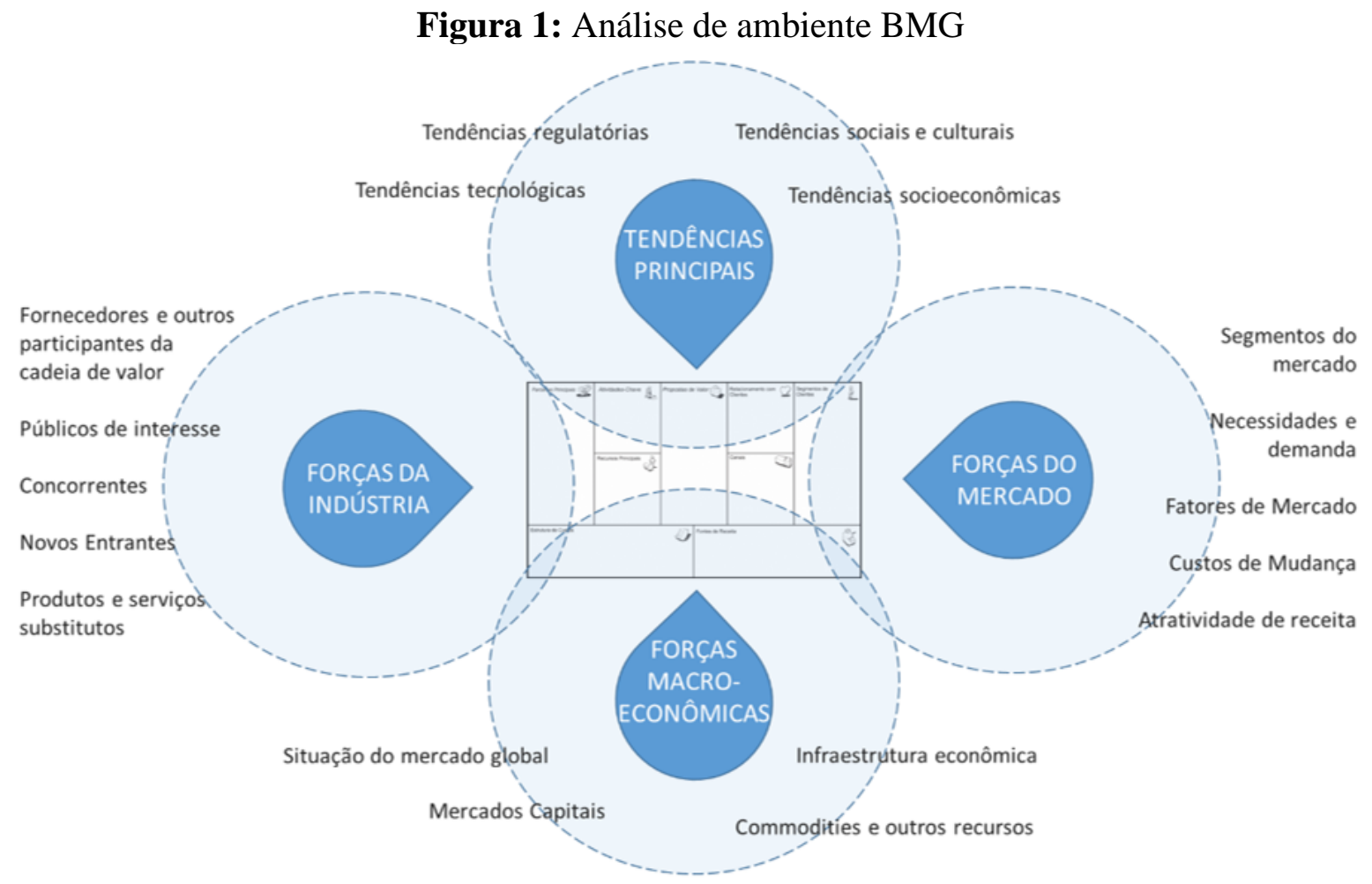

Fonte: Osterwalder e Pigneur (2010)

Assim Osterwalder e Pigneur (2010) descrevem as principais forças externas que influenciam a análise de mercado e as caracterizou utilizando as quatro dimensões mencionadas (Figura 1). A Tabela 1 foi elaborada para explicar, em maior detalhe, essas quatro dimensões. 
Tabela 1 - Mapeamento das quatro dimensões principais

\begin{tabular}{|c|c|c|}
\hline \multirow[t]{5}{*}{$\begin{array}{l}\text { Forças do Mercado } \\
\text { (Análise de } \\
\text { Mercado) }\end{array}$} & Fatores de Mercado & $\begin{array}{l}\text { Identificar questões-chave direcionando e } \\
\text { transformando seu mercado desde os } \\
\text { clientes até perspectivas de ofertas. }\end{array}$ \\
\hline & $\begin{array}{l}\text { Segmentos do } \\
\text { Mercado }\end{array}$ & $\begin{array}{l}\text { Identifica os principais segmentos do } \\
\text { mercado, descreve seus atrativos e busca } \\
\text { localizar novos segmentos. }\end{array}$ \\
\hline & $\begin{array}{l}\text { Necessidades e } \\
\text { Demandas }\end{array}$ & $\begin{array}{l}\text { Descreve as necessidades do mercado e } \\
\text { analisa o quanto elas estão bem atendidas. }\end{array}$ \\
\hline & Custos de Mudanças & $\begin{array}{l}\text { Descreve elementos relacionados aos } \\
\text { clientes alternando negócios aos } \\
\text { concorrentes. }\end{array}$ \\
\hline & $\begin{array}{l}\text { Atratividade de } \\
\text { Receitas }\end{array}$ & $\begin{array}{l}\text { Identifica elementos relacionados à } \\
\text { atratividade de renda e ao poder de preço. }\end{array}$ \\
\hline \multirow{5}{*}{$\begin{array}{l}\text { Forças da Indústria } \\
\text { (Análise de } \\
\text { Competitiva) }\end{array}$} & $\begin{array}{l}\text { Concorrentes } \\
\text { (Incumbentes) }\end{array}$ & $\begin{array}{l}\text { Identifica concorrentes e suas forças } \\
\text { relativas. }\end{array}$ \\
\hline & $\begin{array}{l}\text { Novos Entrantes } \\
\text { (Insurgentes) }\end{array}$ & $\begin{array}{l}\text { Identifica novos entrantes e determina se } \\
\text { eles competem com um Modelo de } \\
\text { Negócios diferente do seu. }\end{array}$ \\
\hline & $\begin{array}{l}\text { Produtos e Serviços } \\
\text { Substitutos }\end{array}$ & $\begin{array}{l}\text { Descreve potenciais substitutos para suas } \\
\text { ofertas - incluindo aqueles de outros } \\
\text { mercados e outras indústrias. }\end{array}$ \\
\hline & $\begin{array}{l}\text { Fornecedores e Outros } \\
\text { Participantes da Cadeia } \\
\text { de Valor }\end{array}$ & $\begin{array}{l}\text { Descreve os participantes principais da } \\
\text { cadeia de valor em seu mercado e detecta } \\
\text { competidores novos e emergentes }\end{array}$ \\
\hline & Público de Interesse & $\begin{array}{l}\text { Especifica quais personagens podem } \\
\text { influenciar sua organização e seu Modelo } \\
\text { de Negócios. }\end{array}$ \\
\hline \multirow[t]{2}{*}{$\begin{array}{l}\text { Tendências } \\
\text { Principais } \\
\text { (Previsão) }\end{array}$} & $\begin{array}{l}\text { Tendências } \\
\text { Tecnológicas }\end{array}$ & $\begin{array}{l}\text { Identifica tendências tecnológicas que } \\
\text { podem ameaçar seu Modelo de Negócios } \\
\text { - ou permitir que ele evolua ou melhore. }\end{array}$ \\
\hline & $\begin{array}{l}\text { Tendências } \\
\text { Regulatórias }\end{array}$ & $\begin{array}{l}\text { Descreve regulamentos e tendências } \\
\text { regulatórias que influenciam seu Modelo } \\
\text { de Negócios. }\end{array}$ \\
\hline
\end{tabular}




\begin{tabular}{|c|c|c|}
\hline & $\begin{array}{l}\text { Tendências Sociais e } \\
\text { Culturais }\end{array}$ & $\begin{array}{l}\text { Identifica as principais tendências sociais } \\
\text { que podem influenciar seu Modelo de } \\
\text { Negócios. }\end{array}$ \\
\hline & $\begin{array}{l}\text { Tendências } \\
\text { Socioeconômicas }\end{array}$ & $\begin{array}{l}\text { Descreve as principais tendências } \\
\text { socioeconômicas relevantes ao seu } \\
\text { Modelo de Negócios. }\end{array}$ \\
\hline \multirow{4}{*}{$\begin{array}{l}\text { Forças } \\
\text { Macroeconômicas } \\
\text { (Análise } \\
\text { Macroeconômica) }\end{array}$} & $\begin{array}{l}\text { Situação do Mercado } \\
\text { Global }\end{array}$ & $\begin{array}{l}\text { Descreve as condições gerais atuais sob } \\
\text { uma perspectiva macroeconômica }\end{array}$ \\
\hline & Mercado de Capitais & $\begin{array}{l}\text { Descreve as condições atuais do mercado } \\
\text { de capitais e as necessidades da empresa } \\
\text { de capitais. }\end{array}$ \\
\hline & $\begin{array}{l}\text { Commodities e Outros } \\
\text { Recursos }\end{array}$ & $\begin{array}{l}\text { Destaca os preços atuais e as tendências } \\
\text { de preço dos recursos exigidos ao seu } \\
\text { Modelo de Negócios. }\end{array}$ \\
\hline & $\begin{array}{l}\text { Infraestrutura } \\
\text { Econômica }\end{array}$ & $\begin{array}{l}\text { Descreve a infraestrutura econômica do } \\
\text { mercado no qual seu negócio opera. }\end{array}$ \\
\hline
\end{tabular}

Fonte: Osterwalder e Pigneur (2010)

\subsection{As 5 Forças competitivas de Porter no contexto da análise dos segmentos industriais}

O modelo das cinco forças de Porter (PORTER, 1979) é uma influente ferramenta de análise estratégica industrial. Sua utilidade se estende de forma ampla, influenciando também a teoria e prática relativa às análises de mercado, enquanto análises que contêm a perspectiva do ambiente externo. Segundo Porter (1979), a análise das forças proporciona melhor entendimento sobre a estrutura do setor, favorecendo uma posição mais rentável e menos vulnerável a ataques.

Essas forças podem ser descritas como: ameaça de novos entrantes, ameaça de produtos e serviços substitutos, poder de negociação dos compradores, poder de negociação dos fornecedores e rivalidade entre os concorrentes. Cada força competitiva tem intensidade variável em função do segmento empresarial. A Figura 2 (abaixo) apresenta um esquema representativo das cinco forças.

Figura 2 - As cinco forças competitivas que moldam a estratégia. 


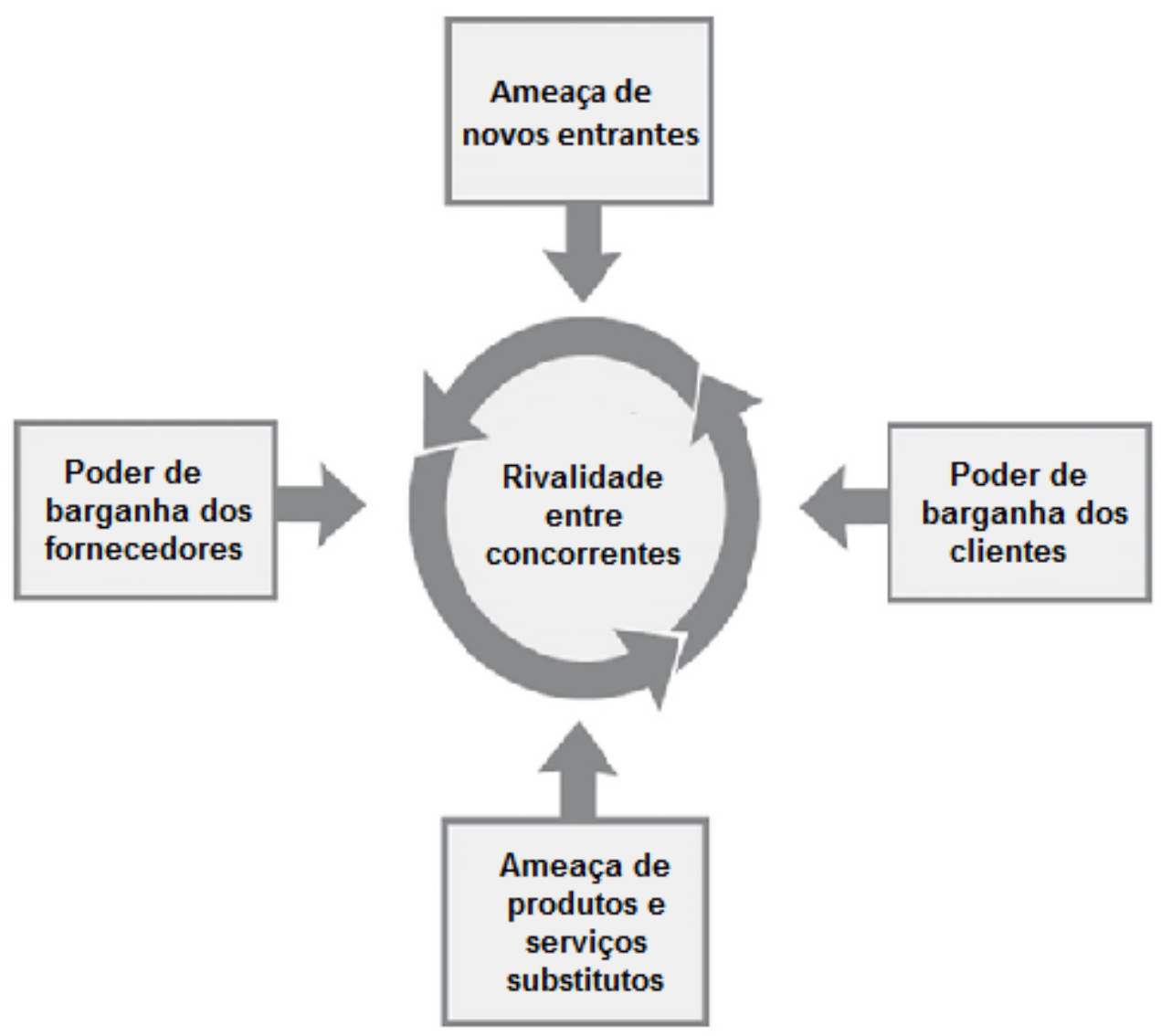

Fonte: Porter (1979)

A primeira força é a "Ameaça de entrada", caracterizada por entrada de novas empresas em um ramo de negócio como objetivo de ganhar parcelas de mercado, o que põe pressão sobre preços, custos e ritmo do investimento necessário para competir (PORTER, 1979). A ameaça de entrada está relacionada às "barreiras de entrada" erguidas pelos líderes e posterior impacto de tal ação na estratégia dos concorrentes.

A segunda força, "Poder de barganha do fornecedor", é representada pela capacidade que o fornecedor tem de negociar com a empresa e influenciá-la fortemente durante tal negociação. Fornecedores poderosos ficam com uma parcela maior do valor ao cobrar mais, limitar a qualidade ou os serviços (PORTER, 1979). Analogamente, os compradores podem também exercer forte poder de barganha, onde se estabelece a terceira força. Porter (1979) afirma que os compradores podem obter para si mais valor ao derrubar preços, exigir maior qualidade ou mais serviços (o que eleva os custos) e, de modo geral, jogar outros participantes do setor uns contra os outros. 
Outra força mencionada é a "Ameaça de produtos ou serviços substitutos", nesse caso, o produto/serviço similar pode oferecer preços mais baixos e até mesmo qualidade mais atraente, limitando o lucro da empresa. Em contrapartida, a ameaça de substituição pode ser favorável a empresa e ter impacto positivo sobre sua rentabilidade futura e o potencial de crescimento (PORTER, 1979).

A última força está relacionada à "Rivalidade entre concorrentes". Essa rivalidade pode ser percebida através de desconto em preços, lançamento de novos produtos, campanhas publicitárias e melhoria em serviços. Para Porter (1979), o impacto da rivalidade sobre o potencial de lucro de uma empresa depende da intensidade da competição no mercado e também da base sobre a qual se dá essa disputa. As bases típicas da disputa são: preço, recursos do produto, serviços de suporte, prazos de entrega, dentre outros.

\section{METODOLOGIA}

Esta pesquisa teve por base a metodologia de estudo de caso. De acordo com Yin (1989), a importância do uso de um estudo de caso se dá pela possibilidade de fazer observações diretas e entrevistas sistemáticas sobre eventos contemporâneos, sendo assim útil pela capacidade de lidar com ampla variedade de evidências - documentos, artefatos, entrevistas e observações. (YIN, 1989) e, em seguida, extrair aprendizagem de tais evidências. O estudo de caso é útil para apreender a complexidade de um caso, incluindo mudanças relevantes ao longo do tempo e atender completamente a condições contextuais, incluindo aquelas que potencialmente interagem com o caso (YIN, 2010).

Foi optado por um estudo de casos múltiplos dadas suas vantagens em termos de redução da vulnerabilidade ao viés do pesquisador e melhor validade externa se comparado ao estudo de caso único (Voss et al., 2002).

Objetivamente, o presente artigo propõe, a partir da teoria, elucidar questões práticas decorrentes da análise da literatura e posterior aplicação, o que resultou na percepção de aspectos importantes no planejamento e condução do estudo de caso.

O estudo de campo foi realizado em um universo de quatro empresas, selecionadas por fazerem análise de mercado e representarem setores comerciais distintos, conforme estruturado na tabela 2. 
Tabela 2 - Especificações das empresas analisadas

\begin{tabular}{|c|c|c|c|}
\hline Empresa & Entrevistado & Segmento & $\begin{array}{c}\text { Número de } \\
\text { Funcionários }\end{array}$ \\
\hline $\begin{array}{c}\text { Empresa de tecnologia } \\
\text { da informação (A) }\end{array}$ & Proprietário & $\begin{array}{c}\text { Venda de Software } \\
\text { gerencial }\end{array}$ & 200 pessoas \\
\hline $\begin{array}{c}\text { Empresa de varejo (B) } \\
\text { Empresa de } \\
\text { consultoria voltada } \\
\text { para gestão } \\
\text { empresarial (C) }\end{array}$ & Proprietário & Alimentício & 31 pessoas \\
\hline $\begin{array}{c}\text { Empresa de tecnologia } \\
\text { da informação para a } \\
\text { área ambiental (D) }\end{array}$ & $\begin{array}{c}\text { Responsável do } \\
\text { marketing }\end{array}$ & $\begin{array}{c}\text { Venda de Software } \\
\text { de legislação } \\
\text { ambiental }\end{array}$ & 20 pessoas \\
\hline
\end{tabular}

Fonte: Elaborado pelos autores

Como forma de estruturar a coleta de dados deste estudo, foi construído um questionário semiestruturado com o intuito de capturar como os aspectos principais de duas publicações influentes da área se relacionam com a prática das empresas analisadas. As publicações citadas são: Business Model Generation (OSTERWALDER e PIGNEUR, 2010) e The Five Competitive Forces That Shape Strategy (PORTER, 1979). O questionário - e a análise posteriormente - se baseou em nove aspectos marcantes dos autores acima citados. São eles: estudo de mercado (em perspectiva ampla); análise de substitutos; análise de concorrentes; análise de novos entrantes; percepção do poder dos clientes; e dos fornecedores; análise de tendências em geral; de custos de mudança e das forças macroeconômicas.

Os conhecimentos adquiridos para a análise foram resultantes da aplicação deste questionário por meio de entrevistas presenciais, todas gravadas, com média de trinta minutos, mediadas por quatro dos presentes autores e direcionadas às pessoas diretamente responsáveis pela análise de mercado dentro das empresas selecionadas.

\section{RESULTADOS E DISCUSSÃO}

Essa seção é destinada a apresentar os resultados do estudo de caso realizado ao longo do desenvolvimento da pesquisa. Para tanto, foram escolhidos aspectos-chave orientadores da 
análise de mercado segundo a literatura escolhida. Em seguida, para cada critério foi feita uma classificação comparativa entre as empresas levando em conta os aspectos: grau de importância para a empresa, nível de formalidade e grau de influência da literatura (OSTERWALDER; PIGNEUR, 2010; PORTER, 1979) durante a prática da análise de mercado. A tabela 3 oferece uma visão macro da análise deste estudo. Nos tópicos posteriores à tabela, tal visão será detalhada.

Tabela 3: Compilação das entrevistas

\begin{tabular}{|c|c|c|c|c|c|}
\hline & \multicolumn{4}{|c|}{ EMPRESAS PESQUISADAS } \\
\hline & & $\mathbf{A}$ & B & $\mathbf{C}$ & D \\
\hline \multirow{9}{*}{ 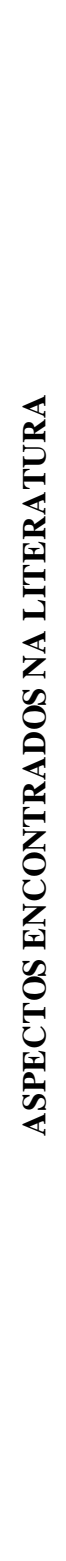 } & $\begin{array}{l}\text { ESTUDO DE } \\
\text { MERCADO }\end{array}$ & $\begin{array}{l}\text { Alta importância } \\
\text { Formal } \\
\text { Alta Influência da } \\
\text { Literatura } \\
\end{array}$ & $\begin{array}{l}\text { Alta Importância } \\
\text { Informal } \\
\text { Baixa influência da } \\
\text { Literatura } \\
\end{array}$ & $\begin{array}{l}\text { Alta importância } \\
\text { Formal } \\
\text { Alta Influência da } \\
\text { Literatura }\end{array}$ & $\begin{array}{l}\text { Alta Importância } \\
\text { Formal } \\
\text { Baixa influência da } \\
\text { Literatura }\end{array}$ \\
\hline & SUBSTITUTOS & $\begin{array}{c}\text { Alta Importância } \\
- \\
\text { Média influência da } \\
\text { Literatura }\end{array}$ & $\begin{array}{l}\text { Alta Importância } \\
\text { Informal } \\
\text { Baixa influência da } \\
\text { Literatura } \\
\end{array}$ & $\begin{array}{l}\text { Baixa Importância } \\
\text { Formal } \\
\text { Média influência da } \\
\text { Literatura }\end{array}$ & $\begin{array}{c}- \\
\text { Formal } \\
\text { Baixa influência da } \\
\text { Literatura }\end{array}$ \\
\hline & CONCORRENTES & $\begin{array}{c}\text { Alta Importância } \\
\text { Formal } \\
\text { Alta Influência da } \\
\text { Literatura } \\
\end{array}$ & $\begin{array}{l}\text { Alta Importância } \\
\text { Formal } \\
\text { Baixa influência da } \\
\text { Literatura }\end{array}$ & $\begin{array}{c}\text { Alta Importância } \\
\text { Formal } \\
\text { Alta Influência da } \\
\text { Literatura }\end{array}$ & $\begin{array}{c}\text { Alta Imortância } \\
\text { Formal } \\
\text { Baixa influência da } \\
\text { Literatura }\end{array}$ \\
\hline & $\begin{array}{c}\text { NOVOS } \\
\text { ENTRANTES }\end{array}$ & $\begin{array}{c}\text { Alta Importância } \\
- \\
\text { Média influência da } \\
\text { Literatura } \\
\end{array}$ & $\begin{array}{c}\text { Média Importância } \\
- \\
\text { Baixa influência da } \\
\text { Literatura } \\
\end{array}$ & $\begin{array}{c}\text { Baixa Importância } \\
- \\
\text { Alta influência da } \\
\text { Literatura } \\
\end{array}$ & $\begin{array}{l}\text { Alta Importância } \\
\text { Formal } \\
\text { Baixa influência da } \\
\text { Literatura } \\
\end{array}$ \\
\hline & $\begin{array}{l}\text { PODER DO } \\
\text { CLIENTE }\end{array}$ & $\begin{array}{l}\text { Média Importância } \\
\text { Informal } \\
\text { Média influência da } \\
\text { Literatura } \\
\end{array}$ & $\begin{array}{c}\text { Baixa Importância } \\
- \\
\text { Baixa influência da } \\
\text { Literatura }\end{array}$ & $\begin{array}{c}- \\
\text { Formal } \\
\text { Alta influência da } \\
\text { Literatura }\end{array}$ & $\begin{array}{c}- \\
- \\
\text { Baixa influência da } \\
\text { Literatura }\end{array}$ \\
\hline & $\begin{array}{c}\text { INFLUÊNCIA DOS } \\
\text { FORNECEDOR }\end{array}$ & $\begin{array}{l}- \\
- \\
-\end{array}$ & $\begin{array}{c}\text { Baixa Importância } \\
\qquad- \\
\text { Média influência da } \\
\text { Literatura }\end{array}$ & $\begin{array}{c}- \\
- \\
\text { Alta influência da } \\
\text { Literatura }\end{array}$ & $\begin{array}{c}- \\
- \\
\text { Baixa influência da } \\
\text { Literatura }\end{array}$ \\
\hline & TENDÊNCIAS & $\begin{array}{l}\text { Baixa Importância } \\
\text { Informal } \\
\text { Alta influência da } \\
\text { Literatura } \\
\end{array}$ & $\begin{array}{l}\text { Baixa Importância } \\
\text { Informal } \\
\text { Baixa influência da } \\
\text { Literatura } \\
\end{array}$ & $\begin{array}{c}\text { Alta Importância } \\
\text { Formal } \\
\text { Alta influência da } \\
\text { Literatura }\end{array}$ & $\begin{array}{l}\text { Baixa Importância } \\
\text { Informal } \\
\text { Baixa influência da } \\
\text { Literatura }\end{array}$ \\
\hline & $\begin{array}{l}\text { CUSTOS DE } \\
\text { MUDANÇA }\end{array}$ & $\begin{array}{l}- \\
- \\
-\end{array}$ & $\begin{array}{c}\text { Baixa Importância } \\
- \\
-\end{array}$ & $\begin{array}{c}\text { Alta Importância } \\
- \\
-\end{array}$ & $\begin{array}{l}\text { Baixa Importância } \\
\text { Informalidade } \\
\text { Baixa influência da } \\
\text { Literatura }\end{array}$ \\
\hline & $\begin{array}{c}\text { FORÇAS } \\
\text { MACROECO- } \\
\text { NÔMICAS }\end{array}$ & $\begin{array}{l}\text { Baixa Importância } \\
\text { Informal } \\
\text { Média influência da } \\
\text { Literatura } \\
\end{array}$ & $\begin{array}{l}\text { Baixa Importância } \\
\text { Informal } \\
\text { Baixa influência da } \\
\text { Literatura } \\
\end{array}$ & $\begin{array}{l}\text { Alta Importância } \\
\text { Formal } \\
\text { Alta influência da } \\
\text { Literatura }\end{array}$ & $\begin{array}{l}- \\
- \\
-\end{array}$ \\
\hline
\end{tabular}

Fonte: Elaborado pelos autores 
Os aspectos sobre os quais não foi possível emitir parecer definitivo com base no questionário foram deixados em branco na tabela acima.

\subsection{Análise do grau de importância dos aspectos avaliados}

Com base nos dados provenientes das entrevistas, foi elaborado um gráfico classificativo (gráfico 1), o qual define em níveis de zero a cinco o grau de importância dado pela empresa a determinado aspecto. Os valores foram atribuídos de forma que quanto mais próximo do zero, menor a preocupação em analisar o quesito. Em contrapartida a proximidade de cinco representa uma análise detalhada do item durante a prática do estudo de mercado da empresa.

Gráfico 1: Compilação e pontuação dos aspectos avaliados

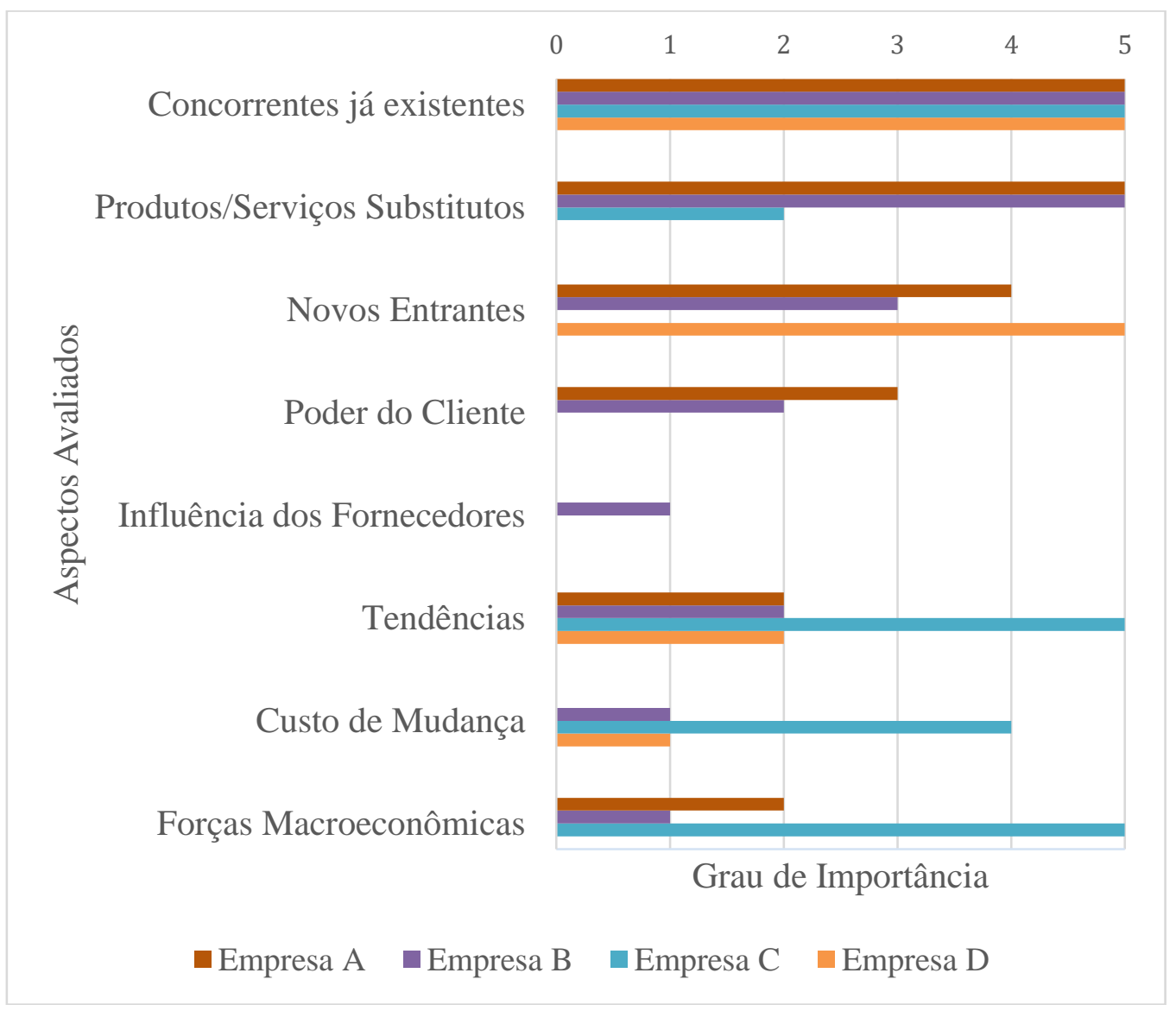

Fonte: Elaborado pelos autores

A partir do gráfico 1, nota-se que o aspecto "concorrentes já existentes" é muito estimado por todas as companhias. Nota-se, portanto, que é um ponto significativo no ambiente competitivo e por isso tende a ser considerada a força mais importante da estratégia (PORTER, 1979), essa afirmativa mostra-se válida para contexto de análise de mercado. Já no campo de ideias 
propostas por Osterwalder e Pigneur (2010) a "análise de tendências" é o único aspecto abordado com algum teor de importância à todas empresas.

\subsection{Análise da formalidade}

Outro fator analisado foi a formalidade com a qual as empresas entrevistadas abordam os aspectos encontrados na literatura. Utilizando os resultados obtidos com a aplicação do questionário foi feita a compilação dos elementos, agrupados em "formal" ou "informal", por meio de uma tabela classificativa (Tabela 3). Partiu-se do princípio de que uma empresa que analisa um aspecto de modo formal utiliza ferramentas e processos com maior nível de detalhamento e estruturação. Já a informalidade é caracterizada por análises desestruturadas, sem seguir frameworks ou processos pré-estabelecidos.

Tabela 3 - Comparação da formalidade entre aspectos avaliados

\begin{tabular}{|c|c|c|c|c|}
\hline \multirow{2}{*}{$\begin{array}{c}\text { ASPECTOS ENCONTRADOS NA } \\
\text { LITERATURA }\end{array}$} & \multicolumn{4}{|c|}{ EMPRESAS PESQUISADAS } \\
\cline { 2 - 5 } & A & B & C & D \\
\hline ESTUDO DE MERCADO & Formal & Informal & Formal & Formal \\
\hline SUBSTITUTOS & Formal & Informal & Formal & - \\
\hline CONCORRENTES & Formal & Formal & Formal & Formal \\
\hline NOVOS ENTRANTES & - & - & - & Formal \\
\hline PODER DO CLIENTE & Informal & - & Formal & - \\
\hline INFLUÊNCIA DO FORNECEDOR & - & - & - & - \\
\hline TENDÊNCIAS & Informal & Informal & Formal & Informal \\
\hline CUSTOS DE MUDANÇA & - & - & - & Informal \\
\hline FORÇAS MACROECONÔMICAS & Informal & - & Formal & - \\
\hline
\end{tabular}

Fonte: Elaborado pelos autores

Através da observação da Tabela 3, é possível verificar que no âmbito do modelo das cinco forças de Porter, apenas o estudo de concorrentes seguiu um padrão formal em todas as empresas. Já perante os aspectos abordados no BMG foi encontrado grande grau de informalidade, sendo que apenas a empresa $\mathrm{C}$ abordou as temáticas de maneira formal.

Por fim, a partir da avaliação das entrevistas, elaborou-se a tabela 4, a qual descreve a influência do referencial teórico nos aspectos "concorrentes já existentes" e "análise de tendências", que foram escolhidos por ter maior grau de importância para as empresas. 


\subsection{Análise da influência da literatura}

A partir da avaliação das entrevistas, elaborou-se a tabela 4, com o objetivo de descrever o grau de influência do referencial teórico escolhido em termos dos aspectos "concorrentes já existentes" e "análise de tendências", que foram escolhidos por ter maior grau de importância para as empresas.

Tabela 4 - Descrição de como ocorre a análise de "concorrentes já existentes", e "análise de tendências" nas empresas

\begin{tabular}{|c|c|c|}
\hline & $\begin{array}{l}\text { Concorrentes já existentes } \\
\text { (PORTER, 1979) }\end{array}$ & Análise de tendências (BMG, 2010) \\
\hline Empresa A & $\begin{aligned} & \text { Alta influência } \\
& \text { Levantamento de } \\
\text { concorrentes por meio de } & \text { planilhas; } \\
& \text { Seleção aprofundada dos } \\
& \text { dados, objetivando separar } \\
& \text { os mais relevantes e úteis. }\end{aligned}$ & $\begin{array}{l}\text { Baixa influência } \\
\text { Levantamento de informações por } \\
\text { meio de: } \\
>\text { Pesquisas online; } \\
>\text { Notícias; } \\
>\text { Discussão da equipe para } \\
\text { analisar a validade das } \\
\text { informações obtidas. }\end{array}$ \\
\hline Empresa B & $\begin{array}{l}\text { Baixa influência } \\
\text { Utilização cliente oculto - } \\
\text { ferramenta para levantar } \\
\text { informações dentro das } \\
\text { empresas concorrentes. }\end{array}$ & $\begin{array}{l}\text { Baixa influência } \\
\text { Levantamento de informações por } \\
\text { meio de: } \\
>\text { Sugestões dos clientes; } \\
>\text { Sugestões em redes sociais, } \\
\text { onde os membros da empresa } \\
\text { enviam notícias, novos } \\
\text { produtos e tendências do } \\
\text { mercado, para analisar se é } \\
\text { viável a introdução dos novos } \\
\text { produtos; }\end{array}$ \\
\hline
\end{tabular}




\begin{tabular}{|c|c|c|}
\hline & & $\begin{array}{l}\text { Participação de feiras da área } \\
\text { como forma de análise de } \\
\text { tendências. }\end{array}$ \\
\hline Empresa C & $\begin{aligned} & \text { Alta influência } \\
& \text { Cliente oculto; } \text { C valor, } \\
& \text { Avaliação através de uma } \\
& \text { matriz de aspectos a } \\
& \text { estabelecendo como: } \\
& \text { serem analisados dos } \\
& \text { concorrentes, as } \\
& \text { avaliação em sites, agamento } \\
& \text { possibilidades de pagan } \\
& \text { e então criando parâmetros } \\
& \text { através de notas. }\end{aligned}$ & $\begin{array}{l}\text { Alta influência } \\
\text { Levantamento de informações por } \\
\text { meio de: } \\
>\text { Uma plataforma paga - } \\
\text { TrendWatching - que traz uma } \\
\text { visão geral de mercado tanto } \\
\text { das macros, quanto das micros } \\
\text { tendências e todas as } \\
\text { inovações que se derivam de } \\
\text { cada uma dessas tendências. }\end{array}$ \\
\hline Empresa D & $\begin{array}{l}\text { Baixa influência } \\
\text { Estudo de resultados sobre } \\
\text { quantos possíveis clientes } \\
\text { estão acessando as redes } \\
\text { sociais dos concorrentes, o } \\
\text { número de curtidas e análise } \\
\text { dos comentários. }\end{array}$ & $\begin{array}{l}\text { Baixa influência } \\
\text { Levantamento de informações por } \\
\text { meio de: } \\
>\text { Pesquisas - através de buscas } \\
\text { na internet e participação de } \\
\text { palestras e workshop em } \\
\text { outros estados. }\end{array}$ \\
\hline
\end{tabular}

Fonte: Elaborado pelos autores

Analisando as quatro empresas de segmentos distintos, observou-se que todas elas utilizam de aspectos descritos no referencial teórico, em maior ou menor nível, para realizar o estudo de ambiente. Porém, apenas as empresas A e C realizam os estudos com plena consciência do arcabouço teórico e realizando a análise de mercado com mais formalidade. Essas empresas explicitaram as referências teóricas e as relacionaram expressamente com as atividades práticas.

\section{CONCLUSÃO}


Esta pesquisa teve como objetivo descrever e analisar o modo como quatro empresas realizam análises de mercado, tendo por base de investigação as teorias expostas no Business Model Generation (OSTERWALDER; PIGNEUR, 2010) e The Five Competitive Forces That Shape Strategy (PORTER, 1979). Por meio de um questionário construído a partir de nove elementos relacionados às duas publicações acima, foi possível analisar a prática das empresas com base em três aspectos principais: i) Atribuição de importância da empresa à análise de mercado; ii) Nível de formalidade na realização da análise e iii) Influência da literatura exposta na prática das empresas.

De modo geral, as organizações exploradas tendem a seguir em maior nível o modelo das cinco forças proposto por Porter. Mas não apresentaram igual ênfase no acompanhamento de aspectos propostos pelo BMG, em especial a análise de tendências e de forças macroeconômicas. Foi também percebida maior formalidade nas empresas que apresentaram maior conhecimento do arcabouço teórico. Outro aspecto elucidado após o desenvolvimento do trabalho foi a assimetria no uso das bibliografias anteriormente citadas.

Como recomendações de pesquisas futuras, seria interessante acompanhar de forma próxima e longitudinal a prática das empresas ao realizar análises de mercado para verificar se a utilização de novos aspectos recomendados pela literatura poderia gerar melhores resultados. Estudar a ligação da influência da literatura ao resultado prático da análise de mercado é também uma questão levantada por este estudo que poderia ser explorada futuramente.

\section{REFERÊNCIAS}

OSTERWALDER, Alexander; PIGNEUR, Yves. Business model generation: a handbook for visionaries, game changers, and challengers. John Wiley \& Sons, 2010.

PORTER, Michael E. The five competitive forces that shape strategy. Harvard business review, v. 86, n. 1, p. 25-40, 2008.

VOSS, C. et al. Case Research in Operations Management. International Journal of Operations and Production Management, v. 22, n. 2, p. 195-219, 2002.

YIN, Robert K. Case Study Research - Design and Methods. Sage Publications Inc., USA, 1989.

YIN, Robert K. Estudo de caso: Planejamento e métodos. Bookman editora, 2015. 